\title{
Article
}

\section{Adsorption Behavior of Arsenic Using Spherical Porous Silica Particles Covered with Magnetite}

\author{
*Kaoru Ohe, Tatsuya Oshima and Yoshinari Baba \\ Department of Applied Chemistry, Faculty of Engineering,, University of Miyazaki, 1-1 Nishi Gakuenkibanadai, \\ Miyazaki 889-2192, Japan \\ Yasuyuki Tagai \\ KINSEI MATEC CO.,LTD, 2-3-7 Hirano-cho, Chuo-ku, Osaka-shi, Osaka 541-0046, Japan \\ Masayuki Shimizu and Toshikazu Miyake \\ Department of Chemical Engineering, Faculty of Engineering, Kansai University, 3-3-35 Yamate-cho, Suita-shi, \\ OSAKA 564-8680, Japan \\ Toshihide Horikawa \\ Department of Chemical Science \& Technology, Faculty of Engineering, The University of Tokushima \\ 2-1 Minamijosanjima-cho, Tokushima 770-8506, Japan
}

(Manuscript submitted April 5, 2007; accepted June 28, 2007)

\begin{abstract}
The adsorption behavior of arsenic from water on spherical porous silica particles(SiMAG) covered with magnetite was investigated under batch equilibrium conditions at $303 \mathrm{~K}$. The specific surface area and the $\mathrm{pH}$ at zero point of charge of SiMAG were $540 \mathrm{~m}^{2} / \mathrm{g}$ and 4.6, respectively. Both of $\mathrm{As}(\mathrm{V})$ and $\mathrm{As}(\mathrm{III})$ were adsorbed on SiMAG. The adsorption of $\mathrm{As}(\mathrm{V})$ increased with decreasing $\mathrm{pH}$, while that of As(III) was slightly dependent on $\mathrm{pH}$. The adsorption capacity of SiMAG towards $\mathrm{As}(\mathrm{V})$ was $0.85 \mathrm{mmol} / \mathrm{g}$.
\end{abstract}

Key words: silica, magnetite, arsenic removal, adsorption, spherical porous particles

\section{Introduction}

Arsenic is a carcinogen and a toxic element for humans. Arsenic is present in nature in both inorganic and organic forms. The toxicity of the inorganic form is higher than the organic form. The arsenic contamination in groundwater has become problem in Asian countries such as India, Bangladesh and China[1-3]. The contamination was caused by arsenic of inorganic form eluted from minerals. The drinking water including arsenic causes skin cancer and damages of liver and lungs for human. The patients of chronic arsenic poisoning have been increasing. In the WHO guidelines, the standard value of arsenic is less than $10 \mathrm{mg} / \mathrm{m}^{3}[4]$. Therefore, removal for arsenic from drinking water and groundwater is very important and urgent.

In order to remove arsenic, many researchers have been developing adsorbents such as iron oxides[5-11] which adsorb arsenic effectively. However since metal oxides are generally obtained as fine powders, their handling is difficult to utilize as the adsorbents[11,12]. In the previous report[10], magnetite particles effectively adsorbed arsenic. The particles containing magnetic materials such as magnetite can be collected easily using magnet. Wakui and co-workers investigated the adsorption of $\mathrm{As}(\mathrm{V})$ using resin beads containing magnetite 
crystals and they reported the maximum capacity was $0.05 \mathrm{mmol} / \mathrm{g}[11]$. Then, in the present study, the spherical porous silica particles as good adsorbent material covered with magnetite(SiMAG) were prepared to investigated the adsorption behavior of arsenic. SiMAG has also spherical porous particles. The porous structure of SiMAG was expected increasing adsorption capacities of arsenic.

\section{Experimental}

\subsection{Materials}

Silica particles covered with magnetite(SiMAG) were obtained by a preparation method reported by Horikawa et al.[12]. Monodisperesed spherical silica particles were prepared using tetraethoxy orthosilicate(TEOS), ethanol and 1-aminododecane of a surfactant as an alkali catalyst at $298 \mathrm{~K}$. The obtained spherical silica particles(wet) were dispersed in an aqueous iron(II) sulfate solution. The suspension was stirred at $298 \mathrm{~K}$ for $24 \mathrm{~h}$. After the resulted product was dried at $383 \mathrm{~K}$, it calcined for $5 \mathrm{~h}$ at $773 \mathrm{~K}$ under $\mathrm{CO}_{2}$.

\subsection{Characterization of SiMAG}

The resulted product was identified by Powder X-ray diffraction(XRD) measurement made on a Rigaku RINT2000/PC with $\mathrm{Cu} \mathrm{K \alpha}$ radiation. The $\mathrm{pH}$ at the zero point of charge $\left(=\mathrm{pH}_{\mathrm{zpc}}\right)$ was determined by an acid-base titration method in $0.1 \mathrm{~mol} / \mathrm{dm}^{3}$ aqueous sodium chloride solution. Specific surface area(=SSA) was calculated by Brunauer-Emmett-Teller(BET) method using the nitrogen adsorption measurement at $77 \mathrm{~K}$ using BELSORP mini(BEL JAPAN, Inc). Surface condition and molar ratio of $\mathrm{Fe} / \mathrm{Si}$ of SiMAG were observed by Scanning electron microscopy(SEM; Hitachi High-Technology, S-4100) and energy dispersive X-ray spectrometer(EDX; HORIBA Ltd., EMAX-5770), respectively.

\subsection{Adsorption experiment}

Adsorption experiments were carried out by a batchwise method. SiMAG of $5 \mathrm{mg}$ was added to 0.08 $\mathrm{mmol} / \mathrm{dm}^{3}$ arsenic solution $\left(20 \mathrm{~cm}^{3}\right)$ and its sample was shaken $(120 \mathrm{rpm})$ at $303 \mathrm{~K}$ for $24 \mathrm{~h}$. The $\mathrm{pH}$ was adjusted using hydrochloric acid and aqueous sodium hydroxide solution. After filtration, the concentrations of As(III) and $\mathrm{As}(\mathrm{V})$ in filtrate were measured by atomic absorption spectrophotometer on a Shimadzu AA6800. Distribution ratio( $\left.\mathrm{cm}^{3} / \mathrm{g}\right)$ was defined as $D=1000 q / C_{e q}$, where $q$ and $C_{e q}$, were the amount of arsenic adsorbed into 1 gram of the adsorbent $(\mathrm{mmol} / \mathrm{g})$ and remaining in $1 \mathrm{dm}^{3}$ of the solution $\left(\mathrm{mmol} / \mathrm{dm}^{3}\right)$, respectively.

\section{Results and Discussion}

\subsection{Characterization of SiMAG}

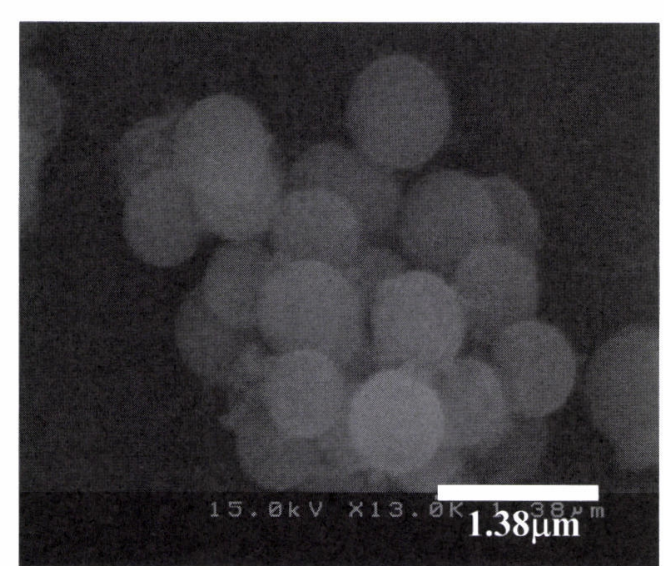

Fig.1 SEM image of SiMAG

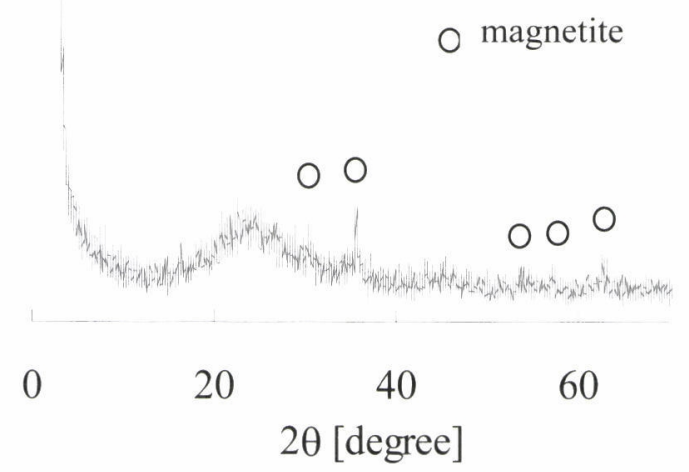

Fig. 2 XRD pattern of SiMAG. 
SiMAG was found to be 700 to $800 \mathrm{~nm}$ particles with smooth surface(Fig.1) with SEM. The BET specific surface area and $\mathrm{pH}_{\mathrm{zpc}}$ were determined as $540 \mathrm{~m}^{2} / \mathrm{g}$ and 4.6 , respectively. XRD pattern of SiMAG is shown in Fig.2. The broad diffraction peak of $2 \theta=25$ degree and the other peaks were assigned to silica and magnetite(JCPDS card No. 19-0629), respectively. A molar ratio of Fe/Si in SiMAG was obtained by EDX to be 0.07 .

\subsection{Effect of the pH}

Figure 3 shows the distribution ratio of $\operatorname{As}(\mathrm{V})$ and $\mathrm{As}(\mathrm{III})$ as a function of $\mathrm{pH}$. Arsenic(V) and As(III) were adsorbed on SiMAG and their adsorption behaviors were different. The adsorption of $\mathrm{As}(\mathrm{V})$ increased with decreasing $\mathrm{pH}$ in the region of $\mathrm{pH} 4-8$. The adsorption of $\mathrm{As}(\mathrm{III})$ increased slightly in the region of $\mathrm{pH} 4-6$ and decreased slightly in the region of $\mathrm{pH}$ 6-8. These similar adsorption tendencies were observed in the case of magnetite[10]. Silica could adsorb slightly $\mathrm{As}(\mathrm{V})$, however As(III) wasn't quite adsorbed [6]. These results should be considered that As(III) and As(V) were adsorbed by magnetite coated on silica. Figure 4 shows the ratio of chemical species of arsenate and arsenite against $\mathrm{pH}$. As you can seen from Fig.4, the predominant species of As(V) and $\mathrm{As}(\mathrm{III})$ are $\mathrm{H}_{2} \mathrm{AsO}_{4}{ }^{-}, \mathrm{HAsO}_{4}{ }^{2-}$ and $\mathrm{H}_{3} \mathrm{AsO}_{3}$, respectively in the region of $\mathrm{pH} 4-8$. Therefore, $\mathrm{As}(\mathrm{V})$ as anion species can be

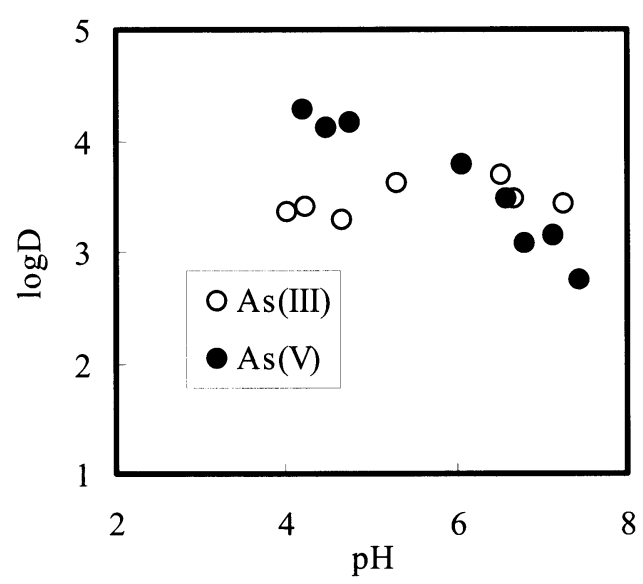

Fig. 3 Effect of $\mathrm{pH}$ on the distribution ratio of $\mathrm{As}(\mathrm{V})$ and $\mathrm{As}(\mathrm{III})$ on SiMAG. (experimental conditions: $5 \mathrm{mg}$ adsorbent in $20 \mathrm{~cm}^{3}$ solution containing 0.08 $\mathrm{mmol} / \mathrm{dm}^{3} \mathrm{As}(\mathrm{V})$ or $\mathrm{As}(\mathrm{III})$ at $303 \mathrm{~K}$. effectively adsorbed by SiMAG, which is due to the electrostatic interaction with positively charged SiMAG. However the adsorption of $\mathrm{As}(\mathrm{V})$ decreased in this $\mathrm{pH}$ region because the electrostatic repulsion was occurred between the negative $\operatorname{As}(\mathrm{V})$ and SiMAG with the negatively charged surface at $\mathrm{pH}>4.6$. On the other hand, As(III) was adsorbed as neutral chemical species, $\mathrm{H}_{3} \mathrm{AsO}_{3}$ on SiMAG. Therefore, it was considered that $\mathrm{As}(\mathrm{III})$ was adsorbed by interaction among $\mathrm{H}_{3} \mathrm{AsO}_{3}$ and hydroxyl groups of SiMAG surface .
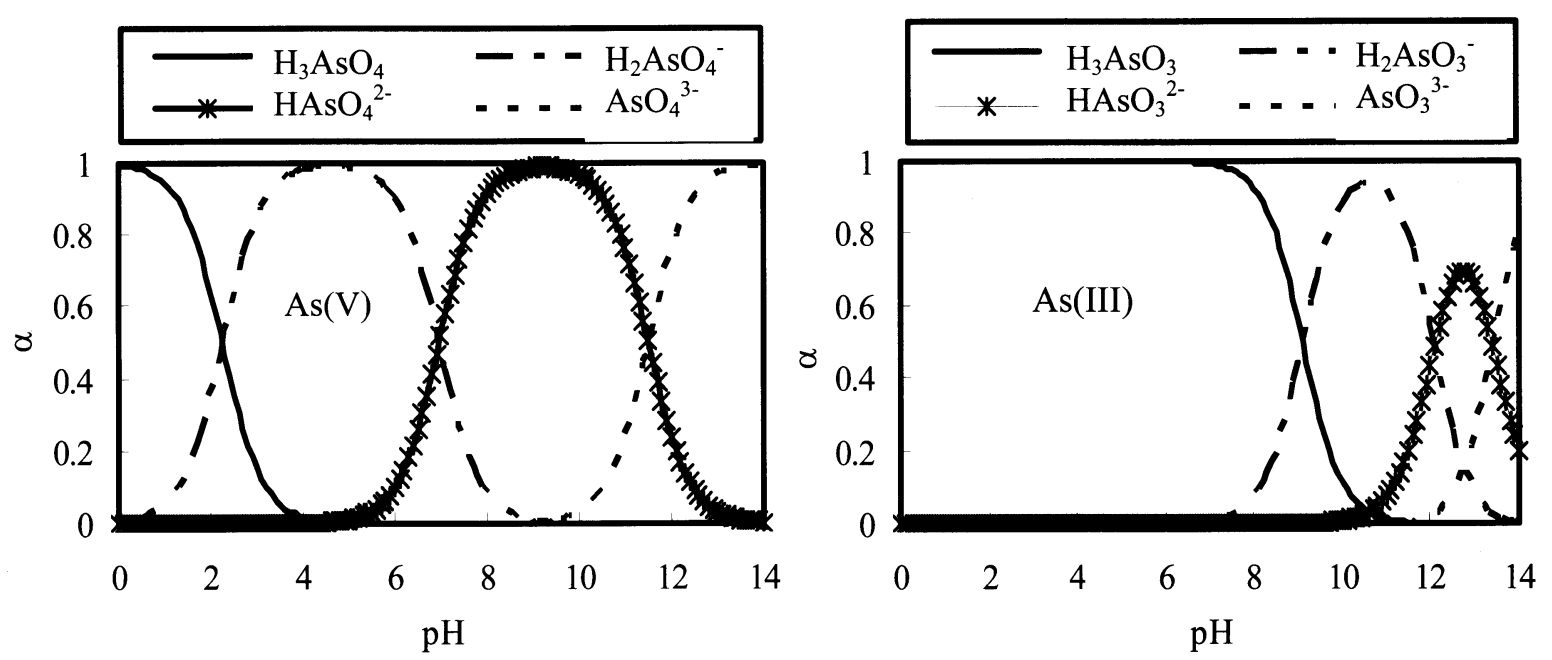

Fig.4 The ratio of chemical species of arsenate( $\mathrm{As}(\mathrm{V}))$ and arsenite(As(III)) against $\mathrm{pH}$. 


\subsection{Adsorption isotherms for $\mathrm{As}(\mathrm{V})$ and $\mathrm{As}(\mathrm{III})$}

Adsorption isotherms were measured for both $\mathrm{As}(\mathrm{V})$ and $\mathrm{As}(\mathrm{III})$ on SiMAG at $303 \mathrm{~K}$. The results are shown in Fig.5. The adsorption behavior can be described by the Langmuir adsorption equation as

$1 / q=1 /\left(K q_{\max } C_{e q}\right)+1 / q_{\max }$

where $K$ and $q_{\max }$ are the adsorption equilibrium constant $\left(\mathrm{dm}^{3} / \mathrm{mmol}\right)$ and adsorption capacity $(\mathrm{mmol} / \mathrm{g})$. Langmuir model was found to fit well for the adsorption of $\mathrm{As}(\mathrm{V})$ and As(III) on SiMAG. The adsorption capacities of $\mathrm{As}(\mathrm{V})$ and $\mathrm{As}(\mathrm{III})$ were $0.85 \mathrm{mmol} / \mathrm{g}$ (approximately 3.5 times for magnetite) and $0.22 \mathrm{mmol} / \mathrm{g}$, respectively. It should be noted that adsorption capacity of $\mathrm{As}(\mathrm{V})$

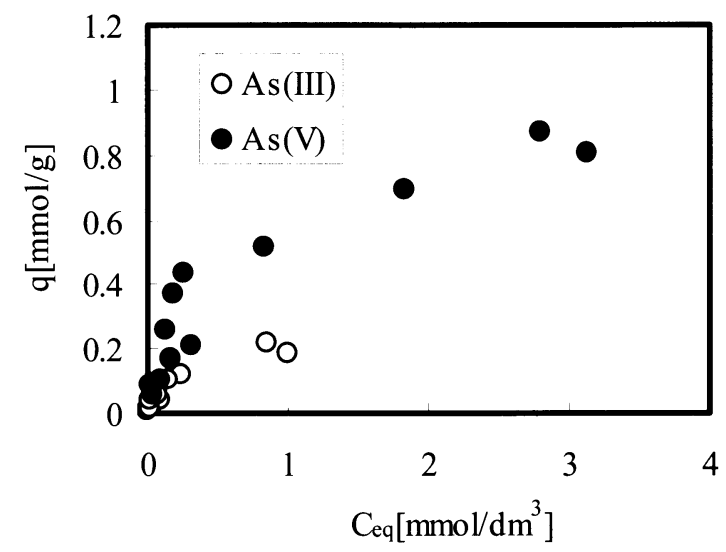

Fig.5 Adsorption isotherms for $\mathrm{As}(\mathrm{V})$ and $\mathrm{As}(\mathrm{III})$ on SiMAG. at $303 \mathrm{~K}$ (experimental conditions: $20 \mathrm{mg}$ adsorbent in $20 \mathrm{~cm}^{3}$ solution $\mathrm{As}(\mathrm{V})$ or As(III) at approximately $\mathrm{pH} 4.5$ ) is much larger than that of $\mathrm{As}(\mathrm{III})$. Silica selectively adsorbed $\mathrm{As}(\mathrm{V})$ in comparison to $\mathrm{As}(\mathrm{III})$. SiMAG was charged positively in lower $\mathrm{pH}$ than its $\mathrm{pH}_{\mathrm{zpc}}$. Therefore, $\mathrm{As}(\mathrm{V})$ existing as anionic species was selectively adsorbed compared with As(III) existing as neutral molecules in lower $\mathrm{pH}$. In spite of a very low molar ratio of $\mathrm{Fe} / \mathrm{Si}(0.07)$, SiMAG had the large adsorption capacity for $\operatorname{As}(\mathrm{V})$. It is expected that the adsorption capacity for $\mathrm{As}(\mathrm{V})$ increases greatly by increasing the molar ratio of $\mathrm{Fe} / \mathrm{Si}$ in SiMAG because the adsorption of $\mathrm{As}(\mathrm{V})$ on magnetite is very larger than on silica.

\section{References}

1) Kadono, T. Inaoka, N. Maruyama, K. Yshijima, M. Nagano, S. Nakamura, C. Watanabe, K. Tmaki, R. Ohtsuka,.(2002), International Journal of Dermatology, 41, 841-846(2002).

2) A. V. Geen, H. Ahsan, A. H. Horneman, R. K. Dhar, Y. Zheng, I. Hussain, K. M. Ahmed, A. Gelman, M. Stute, H. J. Simpson, S. Wallace, C. Small, F. Parvez, V. Slavkovich, N. J. Lolacono, M. Becker, Z. Cheng, H. Momotaj, M. Shahnewaz, A. A. Seddique, and J. H. Graziano (2002), Bulletin of the World Health Organization, 80, 732-737(2002).

3) F.C. Harbey, N. K.,Ashfaque, W.Yu., A. B. M. Badruzzaman,., M.A Ali, M. O. Oate, , H.A. Michael., R.B. Neumann, Chemical Geology, 228, 112-136(2006).

4) The World Health Organization Home Page, http://www.who.int (2007)

5) B.A. Manning, S. E. Fendorf, S. Goldberg, Environ. Sci. Technol.,32, 2383-2388(1998).

6) L. Zeng, Wat Res., 37, 4351-4358(2005).

7) Y. Wakui, T. Ebina, H. Matsunaga and T.M.Suzuki, Anal. Sci., 18, 793-798(2002).

8) H. Fukuoka, N. Shigemoto, H. Inomo and W. Shiraki, J. Chem. Eng. Jpn.,39, 948-955(2006).

9) R.L. Vaughan Jr. and B. E. Reed, Wat. Res., 39, 1005-1014(2005).

10)K.Ohe, Y. Tagai, S. Nakamura, T. Oshima and Y. Baba, J. Chem. Eng. Jpn, 38, 671-676(2005).

11)Y.Wakui, A. E Persulessy, T. Ikeda, T. Ebina, Y. Onodera and T.M.Suzuki, Anal. Sci., 21, 433-435(2005).

12)T. Horikawa, D. Ichimiya, M. Katoh, T. Tomida, J. Hayashi, and Y. Miyake, Proc. Chemica 2005 in Brisbane, Australia(2005) 